\title{
Experimental studies of the arc chamber short circuit failure mechanism on the DIII-D neutral beam system
}

\section{Citation for published version (APA):}

Crowley, B. J., Beckers, J. P., Velasco Enriquez, M., Jaspers, R., Rauch, J. M., Scoville, J. T., Sobota, A., \& Wijkamp, T. A. (2019). Experimental studies of the arc chamber short circuit failure mechanism on the DIII-D neutral beam system. Fusion Engineering and Design, 146, 1605-1609.

https://doi.org/10.1016/j.fusengdes.2019.02.138

\section{Document license:}

TAVERNE

DOI:

10.1016/j.fusengdes.2019.02.138

Document status and date:

Published: 01/09/2019

\section{Document Version:}

Publisher's PDF, also known as Version of Record (includes final page, issue and volume numbers)

\section{Please check the document version of this publication:}

- A submitted manuscript is the version of the article upon submission and before peer-review. There can be important differences between the submitted version and the official published version of record. People interested in the research are advised to contact the author for the final version of the publication, or visit the $\mathrm{DOI}$ to the publisher's website.

- The final author version and the galley proof are versions of the publication after peer review.

- The final published version features the final layout of the paper including the volume, issue and page numbers.

Link to publication

\section{General rights}

Copyright and moral rights for the publications made accessible in the public portal are retained by the authors and/or other copyright owners and it is a condition of accessing publications that users recognise and abide by the legal requirements associated with these rights.

- Users may download and print one copy of any publication from the public portal for the purpose of private study or research.

- You may not further distribute the material or use it for any profit-making activity or commercial gain

- You may freely distribute the URL identifying the publication in the public portal.

If the publication is distributed under the terms of Article 25fa of the Dutch Copyright Act, indicated by the "Taverne" license above, please follow below link for the End User Agreement:

www.tue.nl/taverne

Take down policy

If you believe that this document breaches copyright please contact us at:

openaccess@tue.nl

providing details and we will investigate your claim. 


\title{
Experimental studies of the arc chamber short circuit failure mechanism on the DIII-D neutral beam system
}

\author{
B.J. Crowley ${ }^{\mathrm{a}, *}$, J.P. Beckers ${ }^{\mathrm{b}}$, M. Velasco Enriquez ${ }^{\mathrm{c}}$, R. Jaspers ${ }^{\mathrm{b}}$, J.M. Rauch ${ }^{\mathrm{a}}$, J.T. Scoville ${ }^{\mathrm{a}}$, \\ A. Sobota ${ }^{\mathrm{b}}, \mathrm{T}$. Wijkamp ${ }^{\mathrm{b}}$

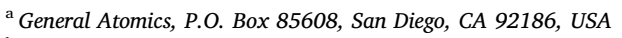 \\ ${ }^{\mathrm{b}}$ Eindhoven University of Technology, Eindhoven, The Netherlands \\ ${ }^{\mathrm{c}}$ National University of Engineering, Lima, Peru
}

\section{A R T I C L E I N F O}

\section{Keywords:}

Neutral beams

Ion source

Fusion

\begin{abstract}
A B S T R A C T
Here we report on efforts to improve performance and longevity of the Neutral Beam Injection (NBI) system by initiating a R\&D program aimed at studying the most common failure mechanism for the ion sources. To this end a filament driven plasma chamber has been constructed with plasma parameters similar to the arc chamber of NBI ion sources. A preliminary report of an investigation into the most common failure is presented here: The failure mechanism observed during helium operations on DIII-D is the result of electrical breakdown of the insulation material that separates the filament plates from the anode. The fault is reproduced in a table top experiment analogous to the DIII-D NBI ion source in key parameters and proposals for amelioration of the issue are discussed.
\end{abstract}

\section{Introduction}

Neutral Beam Injection (NBI) is used for non-inductive heating, current drive, fueling, and diagnostics in most major present and future magnetic confinement fusion devices. The NBI system of the DIII-D device has eight NB injectors each delivering up to $2.5 \mathrm{MW}$ to the tokamak.

The basis for the NBI injector is a hot cathode ion arc chamber [1] of the Common Long Pulse Source design (CLPS) [2]. The CLPS, shown in Fig. 1, was developed in the 1980's and has not been revised since. The principle of operation is a hot cathode comprised of 32 tungsten filaments connected in parallel between two filament plates that are isolated from each other by Mylar gaskets (Mylar is a heat resistant, biaxially-oriented polyethylene terephthalate film). The filament plates are in turn isolated from the anode plate and electron dump (back plate) by isolation plates consisting of copper plates with a Mylar gasket on each side. Another notable feature of the ion source is the probe plate that is close to the extraction plane of the ion source. The purpose of the probe plate is to hold six Langmuir probes that monitor the ion density and provide a signal to the control circuit to keep the ion density in the source constant during beam extraction. The probe plate is also isolated from the rest of the source by Mylar gaskets.

\section{Source reliability}

The CLPS ion sources are subject to some level of deterioration due to operation. The severity of this deterioration depends on the way the device is being operated, such as duration, intensity, and background gas, which is most relevant to this work. Deterioration can decrease performance and may require repairs that are both cost and time expensive. Typically, when operated in deuterium or hydrogen, the sources are refurbished at intervals of approximately one year. Refurbishment entails replacing the insulation gaskets, broken filaments and cleaning the internal surfaces of the arc chamber. However, helium operation is far more problematic and the degradation of the ion sources takes place rapidly after a few days of helium operation. An example of reliability problems caused by operation with helium during the Spring 2016 DIII-D experimental campaign is described in the next paragraph.

The DIII-D NBI system was operated with helium from April 18th through 22nd, 2016, but major issues prevented further operation. At the start of this period six neutral beams were converted for helium usage, but one source failed due to shorting of the chamber after only firing four shots. A second beam failed after two days, resulting in the decision to run the still-operational beams at a decreased performance for the remainder of the campaign. Helium operation led to

\footnotetext{
* Corresponding author.

E-mail address: crowleyb@fusion.gat.com (B.J. Crowley).
} 


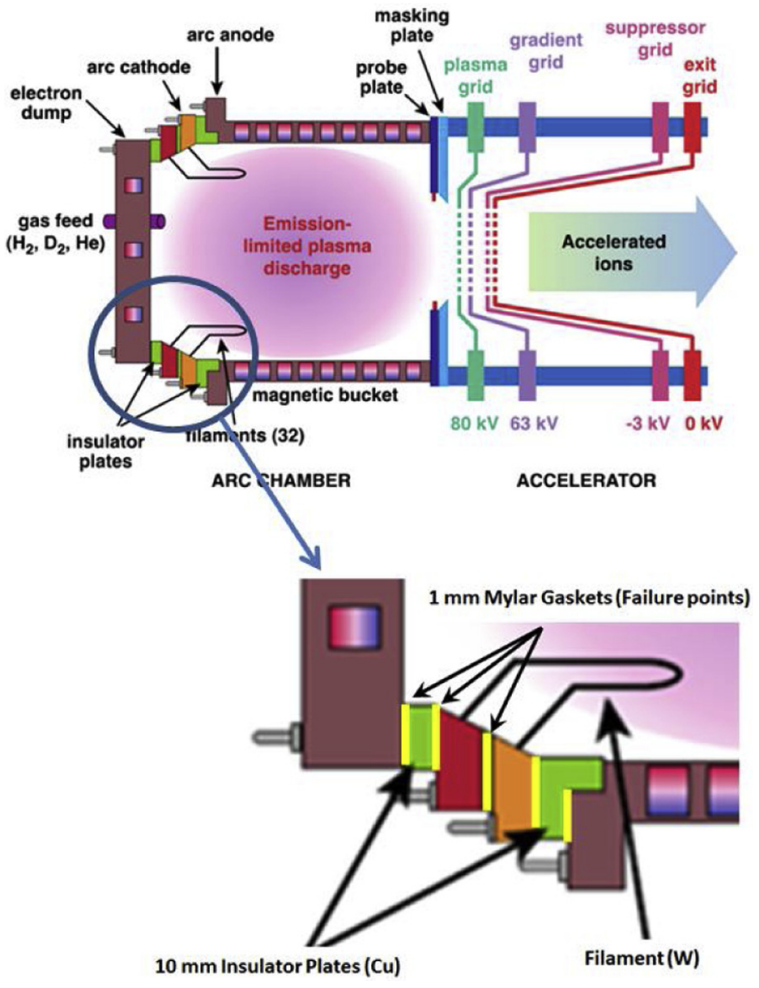

Fig. 1. Sectional view of Common Long Pulse Source with detail of arc and filament plates.

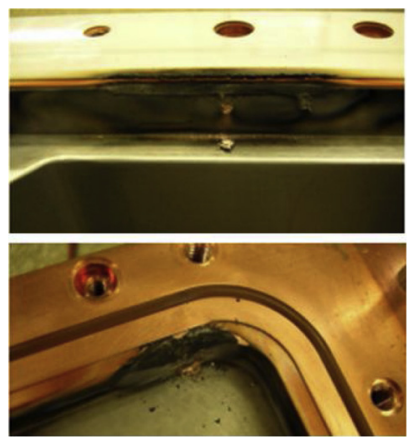

Fig. 2. Damage on the $150^{\circ}$ left arc chamber plate (top) and Mylar gasket. (b) Damage on the $330^{\circ}$ left arc chamber plate (bottom).

deterioration of the insulation between the electrodes of the source. This reduced the plate-to-plate impedances from G $\Omega$ s and $M \Omega s$ to $\mathrm{k} \Omega \mathrm{s}$ and in some cases internal short-circuits. This damage can be seen in Fig. 2, showing photographs of ion source damage at the failure points indicated Fig. 1 sustained after helium operation. The black residue around the breakdown spots is carbonized insulation gasket.

Helium discharges are desirable for some diagnostic purposes, as well as to conduct research relevant for the ITER pre-nuclear phase. ITER will initially run helium and hydrogen discharges [3] but the ability of DIII-D to run helium plasmas is limited by poor performance of the NBI system in helium, hence the motivation for this research.

\section{Miniature arc chamber experiment (MACE)}

MACE was conceived in order to develop solutions to the helium issue as well as other potentially limiting issues germane to the arc chamber. It was designed to be a flexible table top experiment analogous to the CLPS in key parameters (see Table 1).
Table 1

Operational parameters and limits of both the MACE and CLPS sources.

\begin{tabular}{llll}
\hline Symbol & Parameter & MACE & CLPS \\
\hline$V_{\text {arc }}$ & Arc Voltage (V) & $0-160$ & $0-120$ \\
$I_{\text {arc }}$ & Arc Current (A) & $0-75$ & $0-1000$ \\
$I_{\text {fil }}$ & Filament Current (A) & $0-120$ & 3000 \\
$P_{O}$ & Gas Pressure (Pa) & $1-10$ & $2-4$ \\
$N_{\text {fil }}$ & No. of Filaments & $2-4$ & 32 \\
$B_{\text {cusp }}$ & Cusp Field (T) & 0.2 & 0.2 \\
& Gas & $\mathrm{H}_{2}, \mathrm{D}_{2}, \mathrm{He}$ & $\mathrm{H}_{2}, \mathrm{D}_{2}, \mathrm{He}$ \\
$\mathrm{Ne}, \mathrm{Ni}$ & Pulse length (s) & 500 & 15 \\
$\mathrm{Te}$ & Plasma Density (m & $\left.<10^{-3}\right)$ & $<18$ \\
& Electron temperature eV & $1-5$ & $3-5$ \\
\hline
\end{tabular}

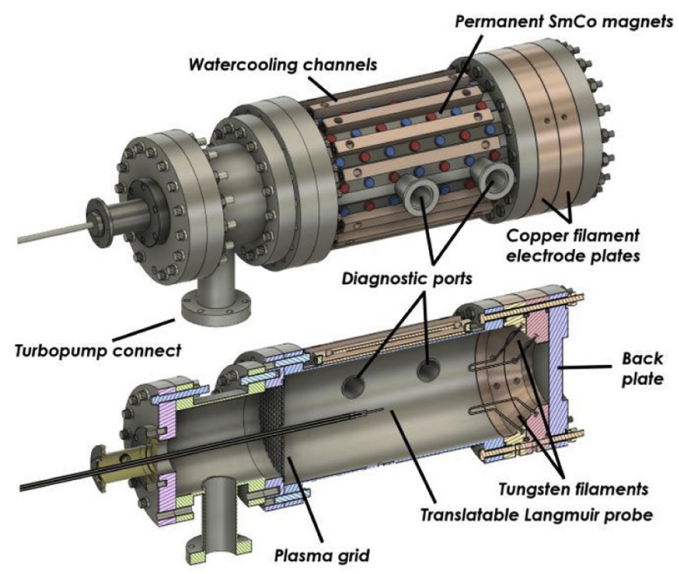

Fig. 3. Digital (CAD) design of the new ion source. The chamber volume is approximately $2.3 \mathrm{~L}$, with a diameter of $12.7 \mathrm{~cm}$.

\subsection{Design}

In Fig. 3 an annotated overview of the components of the novel source is shown. The vacuum compartments consist of the stainless steel main chamber and the auxiliary chamber, which connects to the pumping system. The cylindrical main chamber encompasses the plasma volume, which is limited on the right-hand side by the copper filament electrode plates and back plate, and on the left-hand side by the copper plasma grid. The plasma grid can be moved up and down the central z-axis of the cylinder to allow for a variable plasma volume. This can affect the species densities and is desirable for experimentation.

The copper filament plates have internal connectors that support up to 4 filaments simultaneously. This can be utilized during filament deterioration studies involving a larger number of filaments running at reduced power, which may improve filament lifetime.

The gas is injected through a port at the bottom of the chamber from a gas introduction system consisting of three cylinders $\left(\mathrm{D}_{2}, \mathrm{H}_{2}, \mathrm{He}\right)$, three massflow controllers and a manifold.

\subsection{Control, diagnostics and data acquisition}

An integrated control and data acquisition system was developed on the Python platform for MACE. Several diagnostic systems collect data during a discharge and return essential parameters that provide insight into the physical processes. This is essential for the plasma characterization process, insulation breakdown investigation and any further studies. Multiple electrical sensors provide critical discharge parameters such as current, voltage, and several filament properties. A movable Langmuir probe provides plasma parameters as a function of time and space that are used to characterize and compare the plasma in light of the theory and beam source requirements (Fig. 4). 


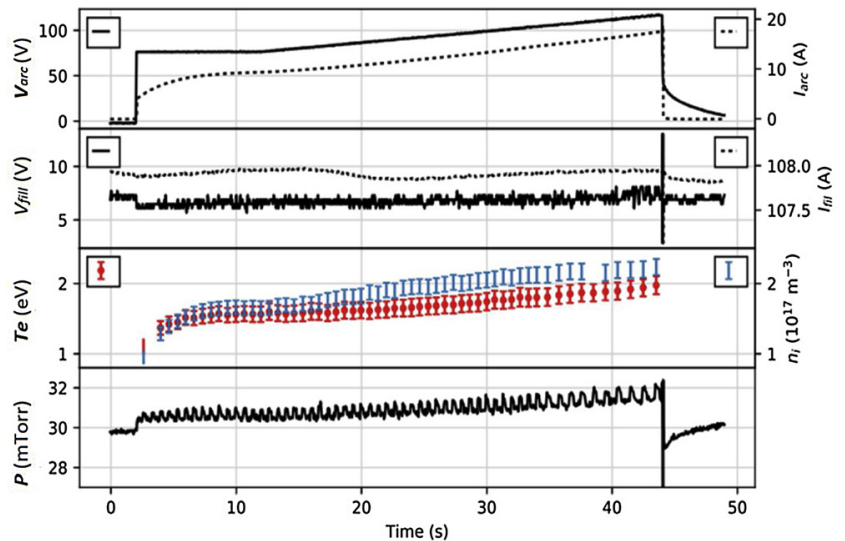

Fig. 4. Typical discharge waveforms in helium, showing the arc and filament electrical parameters (I\&V), electron temperature and ion density obtained from the Langmuir probe, and the pressure as a function of time.

\section{Insulation gasket failure study}

The initial application of MACE is the investigation of the issues surrounding helium operation, particularly the formation of arc spots across the electrode gap. These arc spots, as known in literature [4], arise as highly localized short-circuits between the cathode and anode, and damage the insulation gasket separating these plates. They occur at random locations around the chamber circumference (see Fig. 2). The phenomenon of arc spotting in the CLPS design was described as early as 1985 [5], during the initial commissioning. The sources were subject to 'frequent and severe' arc spotting. At the time it was found that plate materials with a higher melting temperature behaved more favorably in terms of the damage and frequency of arc spots located at the electrode gaps. Consequently several design modifications were made. The modifications reduced the arc spotting severity to a level suitable for source operation in deuterium and hydrogen.

\subsection{Hypothesis}

The main process of such an arc is the thermionic emission from a relatively small, hot spot on the cathode. These are sometimes called 'microspots' in literature. Thermionic emission of electrons from the metal plate surface is sustained by and grows due to ionic bombardment heating. A certain threshold surface temperature initiates this selfsustained arc, which is characterized by the condition that the emission of electrons at that temperature is sufficiently high that the consequent ionization and ionic bombardment supply the cathode spot with the energy required to sustain the local temperature [4]. Several candidate hypotheses are defined:

i Plate heating: It can be hypothesized that ionic bombardment of the cathode plate heats areas of the metal surface to initiate sufficient thermionic emission to ignite an arc.

ii Bombardment carbonization of gasket: Ionic bombardment leads to carbonization of the gasket material, destroying the insulating properties. A direct conductive path now exists from one electrode to another. A current will run across this short-circuit, heating the electrode plates and initiating thermionic emission.

iii Sputtered tungsten deposition: The filament undergoes erosion and vaporization, especially during helium operation. This lost material can be deposited on internal surfaces, coating the gasket with a conductive layer. This conductive path can lead to failure, in a process similar to the one described in hypothesis ii.

iv Cathode self-sputtering: Both the plate heating and gas breakdown may be interpreted as a manifestation of (runaway) self-sputtering of the copper cathode. Helium - and potentially argon - sputters
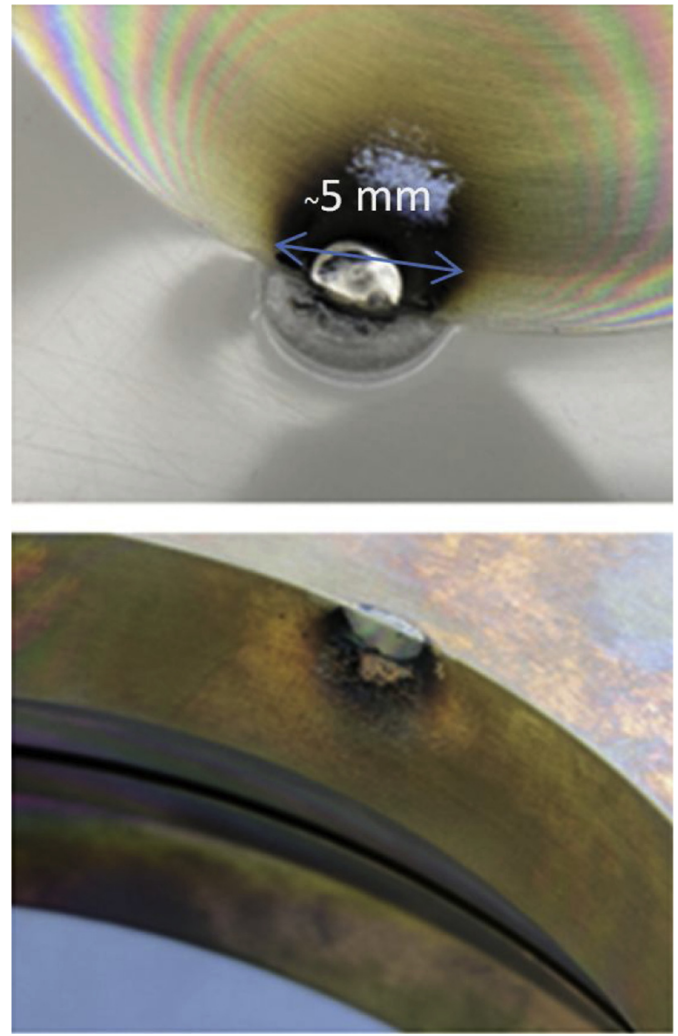

Fig. 5. (Top) Arc spot damage across the insulation gasket on the MACE ion source. The black residue is carbonized Mylar gasket. The Mylar is also molten and fused to the stainless steel flange. (Bottom) Damage to the copper filament plate.

copper particles into the source. These sputtered copper particles have a short ionization mean free path and consequently have a certain probability to return and bombard the cathode surface, creating a self-sustained self-sputtering effect [6]. The consequential release of metal particles with a low ionization potential can lead to the formation of a destructive metal vapor arc.

\subsection{Failure replication}

Each hypothesis involves a mechanism that becomes more severe with increased arc voltage due to increased ion energies and/or sputtering. By ramping the arc voltage beyond $100 \mathrm{~V}$ it was possible to reproduce the failure mode. This occurred at approximately $120 \mathrm{~V}$. During the arc event the discharge current spiked to $>25 \mathrm{~A}$ while the voltage dropped to a fraction of a volt. The initial observations were the destruction of gasket material in a number of spots located at the insulation-plasma interface. Examining the most severe spot (Fig. 5) it is found that a small section of the sandwich of the stainless steel back plate and the copper filament plate had become molten, indicating local temperatures in excess of $1700 \mathrm{~K}$. The arc spotting damage is similar to that observed in CLPS insulation breakdown failures, as shown in Fig. 2.

\subsection{Failure replication in $M A C E$}

During several dry runs (both with and without source gas), where the source is run at high arc voltage without the presence of a plasma, no arc spot formation is observed. As long as a tungsten coating or gasket carbonization is not already present, this is in accordance with the proposed hypotheses.

Some of the hypotheses proposed rely on the formation of a conducting path from one electrode to another that is facilitated by the insulation itself. Specifically, in hypotheses 2 and 3 the presence of and 
plasma interaction of a physical piece of gasket material is critical to the failure mechanism. Thus, recessing the insulation and thereby reducing the exposure of the gasket material to the plasma would improve the reliability of the source. Observational analysis of the recessed gasket indicates that arcing damage occurred around the entire circumference of the chamber, and also inside the gap where insulation was removed. The worst damage was located near the plate edge. The underlying physical reason could be the stronger surface field near this sharp feature. In conclusion, the manifestation of the failure mechanism at work does not require the presence of a piece of exposed insulation (Table 2).

The primary experimental observation relating to the motivation of this work is that the source reliability is diminished during helium operation, indicating that any applicable failure mechanism is more severe under at least one of the conditions involved with helium operation. These are the particular atomic properties of helium, such as ionization energy, operation at higher arc voltages and at higher background pressures. All hypotheses discussed are in agreement with these conditions, however special consideration is required for the plate bombardment heating mechanism. The temperature threshold upon which thermionic emission becomes sufficient to sustain an arc is, in conjunction with others, a function of the amplification enhancement of electron current leaving the cathode. This amplification diminishes in helium due to the increased ionization potential.

The arc spot breakdown takes place regardless of the presence of an insulating gasket, i.e. regardless of the interaction between an insulating surface and the plasma. From this can be deduced that Hypotheses 2 and 3 are not the primary failure mechanisms. Moreover, since these mechanisms accumulate on or affect the entire insulating surface simultaneously, they are not dependent on the gap width. It was found that, on the contrary, an increased gap width seems to reduce the problem of arc spotting. This further decreases the likelihood of these hypotheses.

In literature an empirical equation is found that relates to the threshold current required for the formation of a metal vapor arc [4]. This equation is given by $I_{\text {min }}=2 \cdot 5 \cdot 10^{-4} T_{\text {boil }} \vee \lambda$, in A, where $T_{\text {boil }}$ is the boiling temperature of the metal and $\lambda$ the heat conduction coefficient. Evaluating this threshold current yields $0.17 \mathrm{~A}$ for a stainless steel electrode, 1.4 A for copper, and 1.9 A for tungsten. The discrepancy between copper and stainless steel corresponds to experiments, where it was found that the arc spotting between the steel copper plates was more frequent and more damaging than between the copper-copper plates. Furthermore, this equation agrees with the empirical observation from [5] that electrode surface materials with higher melting temperature are more breakdown resistant.

Taking into account all the above no firm conclusions can be made on the outcome of the study yet, but the metal vapor arc formation mechanism presented by Hypothesis 4 is strengthened by both past empirical observations and the present study.

\section{Conclusions and future work}

Based on this preliminary conclusion several design modifications that can mitigate the arc spot formation can be considered. The primary method is an increase in gap width from $1 \mathrm{~mm}$ to $12 \mathrm{~mm}$, which can be achieved by replacing Mylar-Copper-Mylar insulating plate with a ceramic (Macor or Silicon Carbide) insulating plate. Additionally, a molybdenum shield covering the gap and overlapping the electrode edges, as described in [5], could be developed and tested on the small source. Furthermore placement of permanent high temperature magnets in the electrode near the gap could be considered, which would create additional magnetic cusps in the gap vicinity and reduce or entirely prevent the ionic bombardment of the electrode gap that seems to be at the root of the issue. Lastly, an analysis of potential coating materials, such as plasma sprayed ceramic, for the copper insulator plates may provide a better arrangement than the current mylar-copper-mylar 
configuration.

\section{Acknowledgments}

This material was based upon work supported by the U.S. Department of Energy, Office of Science, Office of Fusion Energy Sciences, using the DIII-D National Fusion Facility, a DOE Office of Science user facility, under Award No. DE-FC02-04ER54698. This work was also supported by EUROfusion through The European Fusion Education Network and by Research Experience for Peruvian Undergraduates (REPU) program.

\section{References}

[1] K.W. Ehlers, K.N. Leung, Rev. Sci. Instrum. 50 (November) (1979) 1353-1361.

[2] Wulf B. Kunkel, Rev. Sci. Instrum. 61 (1990) 354-359, https://doi.org/10.1063/1. 1141292.

[3] A. Polevoi, et al, Nucl, Fusion 53 (2013) 123026.

[4] Y.P. Raizer, Gas Discharge Physics, Springer-Verlag, 1991.

[5] M.C. Vella, et al., NovemberProceedings of 11th Symposium on Fusion Engineering1985, Proceedings of 11th Symposium on Fusion Engineering (1985).

[6] A. Anders, S. Anders, M.A. Gundersen, A.M. Martsinovskii, IEEE Trans. Plasma Sci. 23 (June) (1995) 275-282. 